\title{
Управляемые дифракционные решетки на основе периодической бинарной ориентации нематического жидкого кристалла
}

\author{
К.Г. Комяк, О.С. Кабанова, И.И. Рушнова, Е.А. Мельникова, А.Л. Толстик \\ Белорусский государственный университет \\ fiz.komyak@bsu.by
}

Жидкие кристаллы (ЖК) представляют собой уникальный класс мягких органических материалов, сочетающих свойства жидкостей с определенной степенью ориентационной упорядоченности молекул. Способность самоорганизовываться в сложные структуры, высокая чувствительность к воздействию внешних полей (электрических, тепловых, оптических) обуславливают высокую востребованность ЖКматериалов в области создания фотонных компонент, таких как оптические фильтры, переключатели, дифракционные решетки, массивы линз, вортекс ретардеры, пространственные модуляторы света и др. [1-4] Для создания сложной (локальнонеоднородной) ориентации ЖК применяются различные способы, включая использование электродов специальной конфигурации на подложках, микронатирание ориентирующих пленок, а также технологию текстурированной фотоориентации светочувствительных азокрасителей. Бесконтактный метод фотоориентации ЖКматериалов [5-7] продемонстрировал большие успехи в последние десятилетия и оказался оптимальным для создания периодически упорядоченных одно-, дву- и трехмерных оптических структур, реализующих управление пространственными, фазовыми и поляризационными характеристиками световых полей.

Настоящая работа посвящена изучению дифракционных свойств электрически управляемых одномерных решеток с периодической бинарной ориентацией нематического ЖК, изготовленных методом текстурированной фотоориентации пленок азокрасителя.

На рисунке 1 приведены схемы бинарных дифракционных структур, характеризующихся периодической твист-планарной ориентацией ЖК (рис. $1, a$ ), и периодической твист-твист ориентацией с противоположным направлением закрутки ЖК в смежных доменах (рис. 1, в).

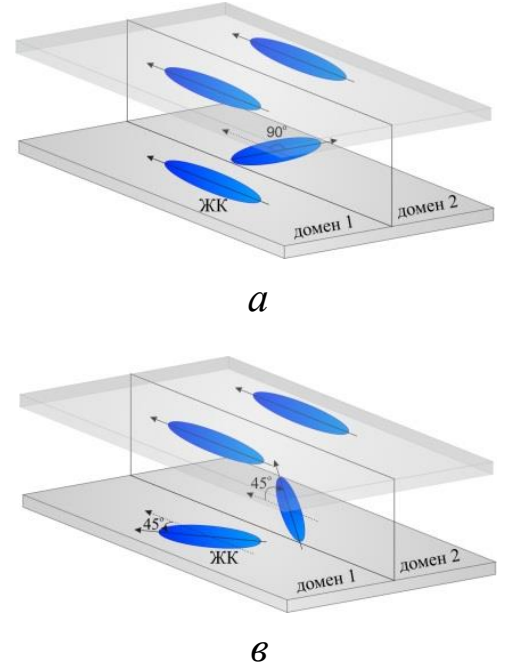

B

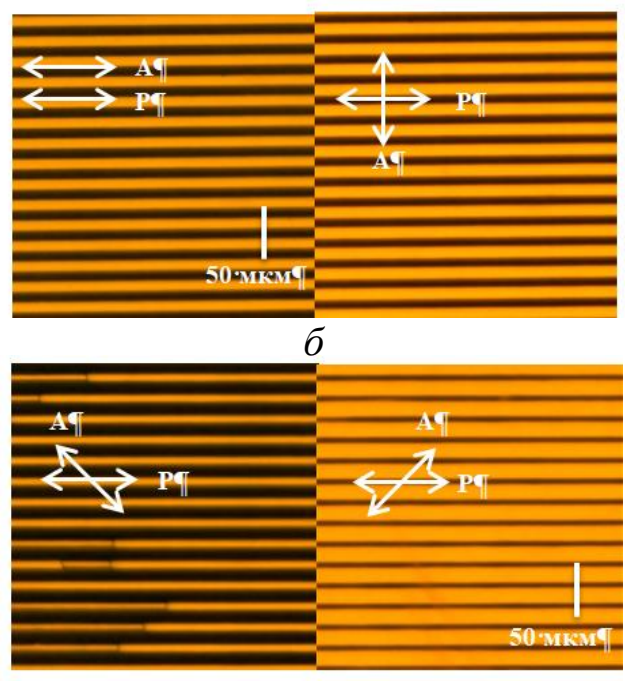

2

Рис. 1 - Схема $(a, b)$ и соответствующие поляризационные микрофотографии $(6,2)$ бинарных дифракционных структур с периодической твист-планарной ориентацией ЖК и с периодической твисттвист ориентацией, характеризующейся противоположным направлением закрутки ЖК в смежных доменах, при напряжении $U=0$ 
Функциональную основу бинарных дифракционных структур составляют тонкопленочные слои нематического ЖК-материала (ЖК 1282, НИОПИК, Россия: $\left.n_{o}=1,678 n_{e}=1,509\right)$ с многодоменной ориентацией. Для изготовления ЖК-ячеек типа сэндвича использовались стеклянные подложки, равномерно покрытые токопроводящим слоем оксида индия-олова (ITO) с сопротивлением порядка 50 Ом/ロ. В качестве фотоориентируемого материала был выбран светочувствительный азокраситель AtA-2 [8,9], синтезированный в ЛМТЖКУ ИНХМ НАН Беларуси. Формирование ориентирующих свойств пленок азокрасителя AtA-2 происходит при облучении их линейно поляризованным светом $(\lambda=465$ нм), причем направление наведенной ориентации перпендикулярно направлению поляризации активирующего излучения. Тонкие пленки азокрасителя AtA-2 наносились на тщательно очищенную внутреннюю поверхность подложек методом род коутинга. Облучение подложки $A$, содержащей периодически чередующиеся ЖК-домены, реализовывалось с помощью одномасочного процесса, включающего двухэтапную экспозицию пленки линейно поляризованным излучением светодиодной матрицы ( $\left.\lambda=465 \mathrm{Hм}, P=60 \mathrm{мBт} / \mathrm{cm}^{2}\right)$. После первого этапа равномерного облучения поверхности пленки производилось повторное облучение через амплитудную фотомаску, что позволило изменить направление ориентирующих структур в немаскированных областях путем поворота плоскости поляризации активирующего излучения на угол $90^{\circ}$. Подложка $B$ экспонировалась линейно-поляризованным излучением равномерно. Применение указанного алгоритма экспонирования подложек позволило изготовить два типа бинарных дифракционных ЖК-структур (период 20 мкм): с чередующимися твист $\left(\beta=90^{\circ}\right) /$ планарными доменами и с чередующимися противоположно закрученными твист доменами $\left(\beta_{1}=45^{\circ}\right.$ и $\left.\beta_{2}=-45^{\circ}\right)$, где $\beta$ - угол закрутки ЖК. Толщина нематического ЖК-слоя контролировалась при помощи волоконных спейсеров и составляла $d=20$ мкм.

Для изучения дифракционных свойств изготовленных бинарных ЖК-решеток использовался He-Ne-лазер, генерирующий узконаправленный луч линейно поляризованного света с длиной волны 632,8 нм и фотодетектор. Для исследования состояния поляризации дифрагированных световых пучков использовался анализатор. На рисунке 2 приведены зависимости дифракционной эффективности от напряжения 0го и 1-го порядков для двух типов ЖК-решеток.
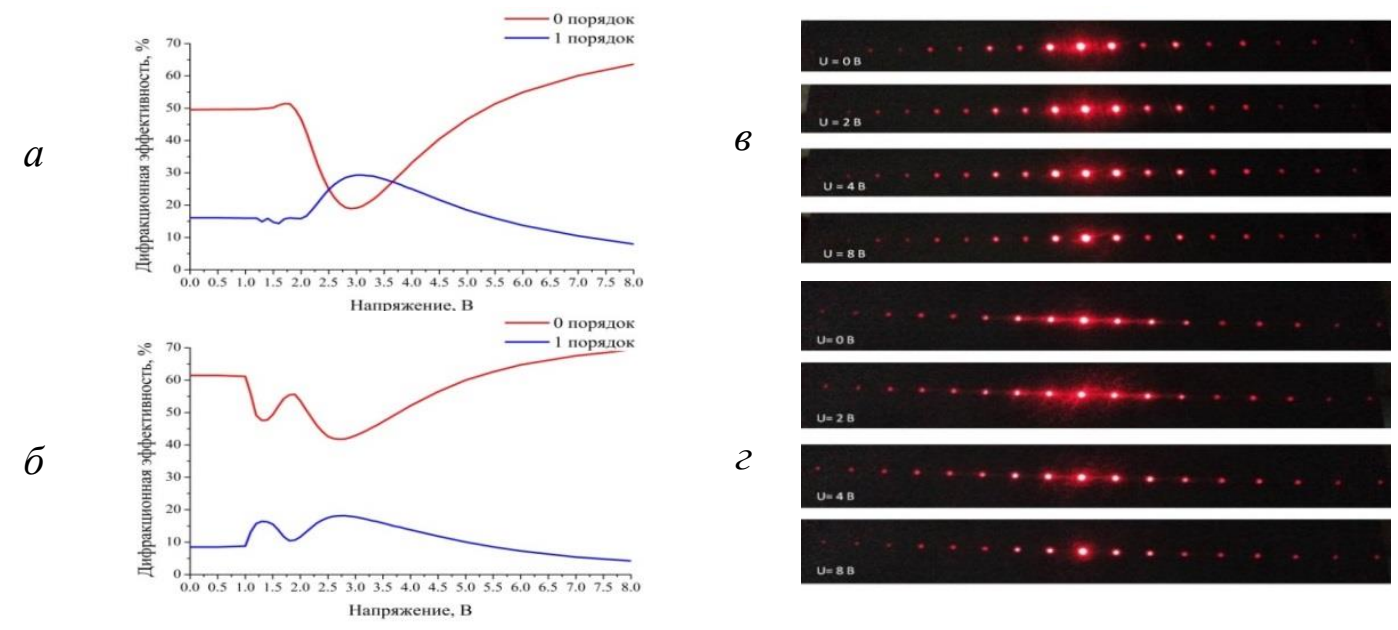

Рис. 2 - Зависимости картин дифракции $(6,2)$ и дифракционных эффективностей 0-го и 1-го порядков от напряжения $U$ для бинарных решеток с твист-планарной ориентацией ЖК-доменов $(a, b)$ и с противоположно закрученной твист-твист ориентацией ЖК-доменов $(\sigma, 2)$ 
Характерной особенностью решетки с твист-планарной ориентацией ЖК доменов является значительное уменьшение интенсивности четных дифракционных максимумов при $U=0$ (рис. 2,8 ), что указывает на прямоугольный профиль штриха. При напряжении на ячейке $U=3,0$ В для данной решетки наблюдается значительный рост дифракционной эффективности 1-го порядка с $16 \%$ до $29 \%$, при этом дифракционная эффективность 0-го порядка уменьшается с $49 \%$ до $19 \%$ (рис. 2, a). Дальнейшее увеличение напряжения сопровождается переориентацией ЖК под действием электрического поля, что приводит к постепенному исчезновению дифракционных свойств ячейки. Решетка с противоположно закрученной твист-твист ориентацией ЖКдоменов характеризуется относительно меньшими значениями дифракционных эффективностей: $61 \%$ для 0 -го и $8 \%$ для 1-го порядков дифракции при $U=0$ (рис. 2, б). При напряжениях на ячейке $U_{l}=1,35 \mathrm{~B}$ и $U_{2}=2,70 \mathrm{~B}$ наблюдается уменьшение дифракционной эффективности 0 -го порядков, сопровождающееся увеличением дифракционной эффективности 1-го порядка. Дальнейшее увеличение напряжения в силу переориентации ЖК приводит к постепенному исчезновению дифракционных свойств ячейки.

На рисунке 3 приведены результаты экспериментального исследования состояния поляризации световых пучков, дифрагированных в 0-ой и 1-ый порядки.

Падающее излучение
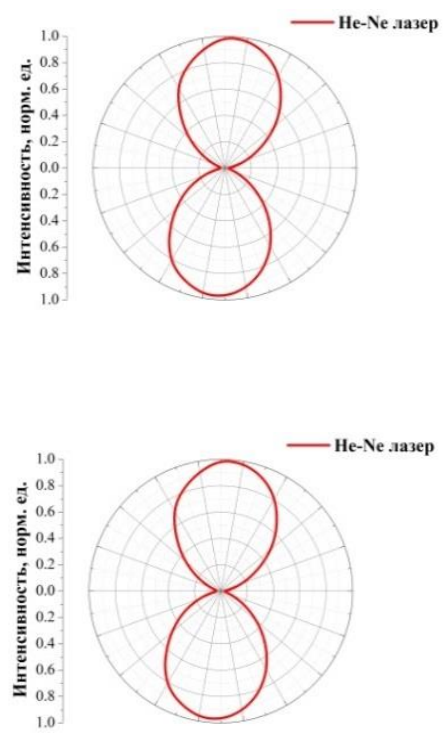

Бинарная решетка с твистпланарной ориентацией ЖК

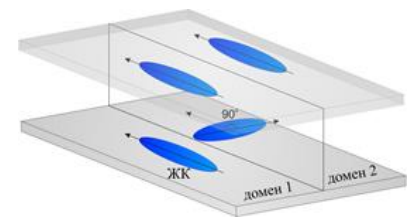

Бинарная решетка с противоположно закрученной твист-твист ориентацией ЖК

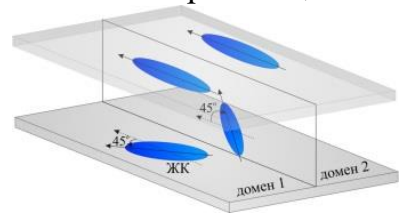

Прошедшее излучение (0 порядок дифракции)
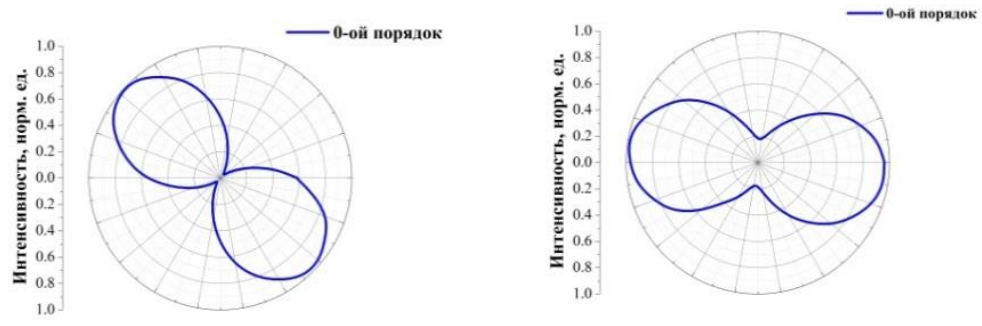

1 порядок дифракции
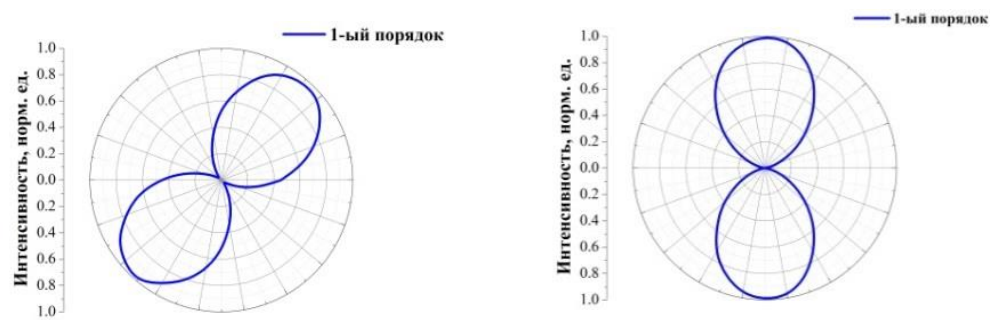

Рис. 3 - Состояния поляризации прошедшего и дифрагированных в 1-ый порядок световых пучков для бинарных решеток с твист-планарной ориентацией ЖК-доменов и с противоположно закрученной твисттвист ориентацией ЖК-доменов. Направление поляризации падающего излучения является вертикальным 
Согласно полученным экспериментальным данным (рис. 3), имеет место поворот направления поляризации прошедшего излучения на угол $\alpha_{01}=45^{\circ}$ для бинарной решетки с твист-планарной ориентацией ЖК-доменов и на угол $\alpha_{02}=90^{\circ}$ для бинарной твист-твист решетки с противоположно закрученными ЖК-доменами. Вместе с этим, поляризация дифрагированного в 1-ый порядок излучения поворачивается на угол $\alpha_{11}=-45^{\circ}$ в случае бинарной решетки с твист-планарной ориентацией ЖК-доменов и остается неизменной для бинарной твист-твист решетки с противоположно закрученными ЖК-доменами. Следует отметить, что эллиптичность состояния поляризации световых пучков, дифрагированных в 1-ый порядок практически равна 0. Эллиптичность состояния поляризации прошедшего излучения отлична от 0 для решетки с твист-твист конфигурацией.

Таким образом, бинарные ЖК-решетки, изготовленные на основе текстурированной фотоориентации азокрасителя характеризуются электрически управляемыми дифракционными свойствами и позволяют реализовать пространственно-поляризационное управление световыми пучками. Полученные результаты могут использоваться в области разработки и создания современных фотонных устройств и систем управления оптическими полями.

\section{ЛИТЕРАТУРА}

1. D.-K. Yang, S.-T. Wu "Fundamentals of Liquid Crystal Devices" Chichester: John Wiley \& Sons, Ltd, 2014.

2. D Lee. et al. // Adv. Opt. Mater. 2020. V. 2001604. P. 2001604.

3. C. Oh, M.J. Escuti // Opt. Lett. 2008. V. 33. No 20. P. 2287.

4. O.S. Kabanova et al. // J. Belarusian State Univ. Phys. 2019. No 3. P. 4.

5. V.G.Chigrinov, V.M. Kozenkov, H.-S. Kwok "Photoalignment of liquid crystalline materials : physics and applications" Chichester: John Wiley \& Sons, Ltd, 2008.

6. V. Chigrinov, A. Kudreyko, Q. Guo // Crystals. 2021. V. 11. No 2. P. 84.

7. A. Kozanecka-Szmigiel et al. // J. Mater. Chem. C. 2020. V. 8. No 3. P. 968.

8. V. Mikulich et al. // J. Soc. Inf. Disp. 2014. V. 22. No 4. P. 199.

9. V.S. Mikulich et al. // J. Appl. Spectrosc. 2016. V. 83. No 1. P. 115. 